\title{
The Use of Natural Fibers in Repairing and Strengthening of Cultural Heritage Buildings
}

\author{
Ali Abbass ${ }^{1(*)}$, Paulo B. Lourenço ${ }^{2}$, Daniel V. Oliveira ${ }^{3}$ \\ 1, 2, 3 ISISE, University of Minho, Institute of Science and Innovation for Bio-Sustainability (IB-S), Depart. Civil \\ Engineering, Portugal \\ Corresponding author's E-mail address*: id8215@alunos.uminho.pt (A. Abbass), ${ }^{2}$ pbl@ civil.uminho.pt, \\ 3danvco@civil.uminho.pt
}

\begin{abstract}
Natural fibers are getting a huge interest amongst researchers due to their green, economical and good mechanical properties when employed in different composites as reinforcements. In this work we present a review on the applications of natural fibers, essentially as composites, for structural purposes with focus on repairing and strengthening of cultural built heritage. Different testing methods with their results combined with the studying of the enhancements attained by applying natural fiber composites, e.g. textile reinforced mortar (TRM), to weak masonry are discussed. Durability challenges mainly due to the hydrophilic nature of the natural fibers are discussed together with some possible solutions.
\end{abstract}

Keywords: Natural Fibers Composites; Built Heritage; Seismic Retrofitting; Surface Treatments; Masonry

\section{Introduction}

Masonry structures are widespread around the Mediterranean area and Europe. With the various materials used for masonry structures, e.g. clay bricks, tuff and stones, masonry is considered as one of the most used building materials that humans ever used.

The old masonry structures were constructed mainly to resist vertical and gravitational loads, mainly the dead loads [1]. However, historical constructions, in general, are likely to be subjected to various hazards, either natural or man-made, that may threat their functions, behavior and even the continuity of their existence. Various catastrophic natural hazards, namely earthquakes, have happened through time and caused severe casualties and losses. Under such lateral loads, masonry structures showed a vulnerable seismic response [2]. Thus, this problem highlights the necessity to approach scientific interventions to preserve the built heritage against earthquakes.

Amongst the different strengthening systems based on the external retrofitting of historical constructions, the use of external reinforcements embedded into inorganic matrices has had an important consensus among researchers. These composites are employed as textile reinforced mortar/fiber reinforced cementitious matrices, the so-called TRM/FRCM composites, and have been studied and proved a high capability to enhance lateral stiffness and load carrying capacity of historical masonry constructions.

Different types of synthetic fibers have been used as reinforcements, such as basalt, glass and carbon, typically embedded within lime or cement matrices and applied to masonry panels. Consequently, very interesting mechanical enhancements have been attained in terms of both in-plane shear capacity and out-of-plane flexural performance. However, the manufacturing process of synthetic fibers composites, their application and the disposal at end-of-life phase have a harsh impact to the environment. Moreover, compatibility problems pointed out by the over stiffening of masonry substrates combined with the premature cracks occurring before reaching the ultimate capacity of these fibers appeared as drawbacks. Hence, researchers have been motivated to direct their studies to green, economical, and innovative solutions.

Given their environmental-friendly trait, economic feasibility and good mechanical properties, natural fibers have emerged as an alternative solution to many synthetic fibers. The applications of this environmental-friendly solution have spread to major industries such as automobiles, biomedicines and mechanical engineering. 
All the advantageous characteristics corresponding to the use of natural fibers drew the attention to the possibility of engaging them in the structural repairing of the historical constructions. This paper presents an overview on the strengthening and repairing works resorting to natural fibers with a major focus on the cultural built heritage and the challenges corresponded to.

\section{Natural Fibers and Civil Engineering}

Due to the aforementioned significant benefits provided by natural fibers, their applications were widened to be exploited in civil engineering purposes. Among different natural fibers, such as animal (wool, silk. etc.), cotton and processed cellulosic fibers, bast fibers derived from plants are most widely investigated and used for building materials purposes [3]. Flax, hemp, sisal and kenaf have good mechanical properties if compared to synthetic fibers, as shown in Table 1 described by author [4].

Table 1-Bast natural fibers mechanical properties [4].

\begin{tabular}{lcccccc}
\hline \multicolumn{1}{c}{ Fiber } & Density & Diameter & Tensile Strength & Young's modulus & $\begin{array}{c}\text { Elongation } \\
\text { at break }\end{array}$ & \multirow{2}{*}{ References } \\
\cline { 2 - 5 } & $\mathrm{g} / \mathrm{cm}^{3}$ & $\mu \mathrm{m}$ & $\mathrm{MPa}$ & $\mathrm{GPa}$ & $\%$ & \\
\hline Cotton & $1.5-1.6$ & - & $287-800$ & $5.5-12.6$ & $7.0-8.0$ & 45,49 \\
Jute & $1.3-1.45$ & $25-200$ & $393-773$ & $13-26.5$ & $1.16-1.5$ & $22,23,37,45,49$ \\
Flax & 1.50 & - & $345-1100$ & 27.6 & $2.7-3.2$ & $22,23,37,49$ \\
Hemp & - & - & 690 & - & 1.6 & 2237 \\
Ramie & 1.50 & - & $400-938$ & $61.4-128$ & $1.2-3.8$ & 22374649 \\
Sisal & 1.45 & $50-200$ & $468-640$ & $9.4-22.0$ & $3-7$ & 2223374549 \\
PALF & - & $20-80$ & $413-1627$ & $34.5-82.51$ & 1.6 & 45 \\
Coir & 1.15 & $100-450$ & $131-175$ & $4-6$ & $15-40$ & 22,45 \\
E-glass & 2.5 & - & $2000-3500$ & 70 & 2.5 & 22,47 \\
S-glass & 2.5 & - & 4570 & 86 & 2.8 & $22,23,47$ \\
Aramid & 1.4 & - & $3000-3150$ & $63-67$ & $3.3-3.7$ & 22,47 \\
Carbon & 1.7 & - & 4000 & $230-240$ & $1.4-1.8$ & 22,47
\end{tabular}

One of the most significant applications of natural fibers in construction field is the use of short fibers as internal reinforcements mainly to increase the tensile and flexural properties. When reinforced with randomly distributed short natural fibers, cement concrete showed a higher toughness after the occurring of cracking [5]. The crossed fibers along the crack width demonstrated the so-called bridging phenomena, see Figure 1, an issue that highlights the capacity of natural fibers to transfer stresses. For instance, Li et al. [6] employed $20 \mathrm{~mm}$-long hemp fibers when casting reinforced concrete and detected increase of flexural toughness by $144 \%$, combined with increased flexural toughness index by $214 \%$. These results were in consensus with results acquired with author [7], where a set of different natural fibers were used to reinforce concrete prismatic samples, see Figure 2. Hemp fibers showed the highest fracture energy increment of $70 \%$ when compared to non-reinforced concrete samples.

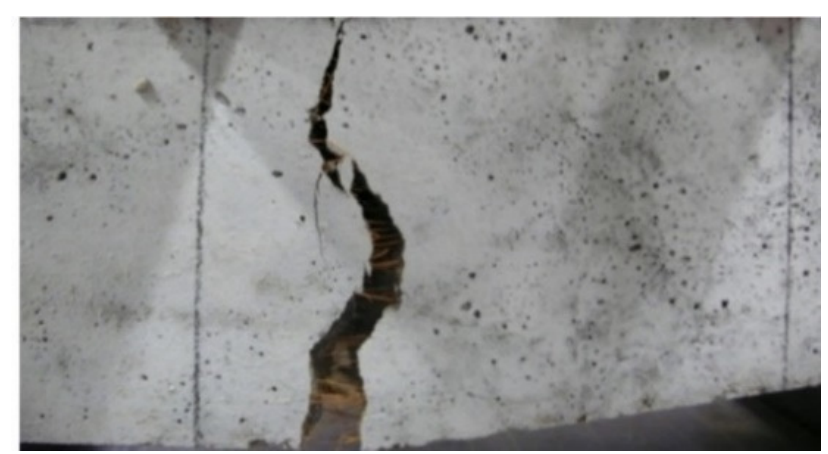

Figure 1-Coconut fibers-reinforced concrete [5]. 

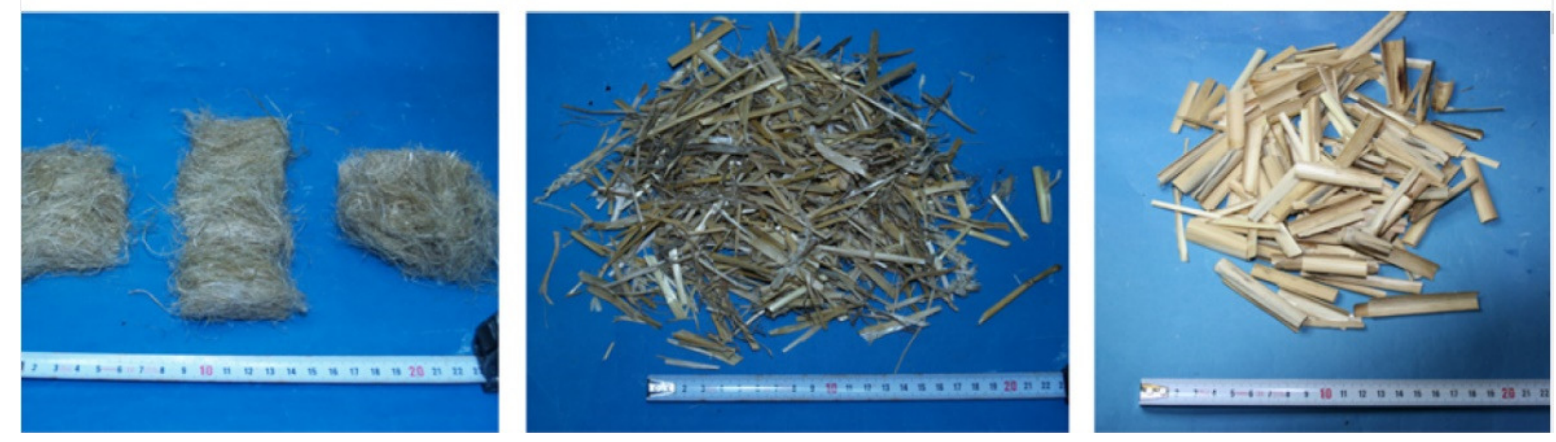

Figure 2-Hemp, wheat straw, and elephant grass, respectively [7]

Natural fibers can also be studied as possible reinforcements for polymeric concrete resulting in increased flexural strength [8]. Depending on the kind and the proportion of natural fibers, mechanical behavior improvements of the reinforced samples can be achieved without compromising the compressive characteristics of the concrete. B. Hu et al [9] studied short sisal and ramie fibers, independently, as possible reinforcements for epoxy polymer concrete and the flexural strength was increased by $10 \%$ and $25 \%$ for both fibers respectively. Also, Reis [10] studied a set of natural fibers to reinforce epoxy resins polymer concrete with banana, coconuts and bagasse fibers. Subsequently, it was stated that increments in both fracture toughness and fracture energy ( $16 \%$ and $41 \%$ respectively) when using coconut and bagasse fibers were observed.

For non-cementitious materials, such as rammed earth [11], natural fibers were examined in literature as apt reinforcements when fabricating adobe bricks [12]. Given the brittle properties of adobe bricks, the addition of natural fibers resulted in improving their breaking behavior. Millogo et al. [13] observed that the addition of short hemp fibers $(30 \mathrm{~mm})$ at proportion of $0.2-0.6 \mathrm{wt} \%$ led to limitations of the porosity of the bricks that resulted in better mechanical characteristics. Moreover, the high adhesion with clay matrix ensued in higher durability, according to abrasion tests, as well as improved flexural strength because of the high tensile strength of the fibers. The addition of $1 \mathrm{wt} \%$ of straw fibers to mud adobe contributed to developments in energy absorption and ultimate load capacities by acting as shear reinforcements [14]. The stabilization with coconut husk, bagasse and oil palm fibres in the production of red and brown clayey soil blocks was studied by Danso et al. [15]. The results revealed that a $0.5 \mathrm{wt} \%$ content of the fibers to soil improved significantly the compressive strength (up to $57 \%$ with palm oil fibers), erosion resistance and reduced shrinkage cracking. Considerable ductility [11], resistance (around 24\% increment) and elasto-plastic behavior were also obtained by Jové-sandoval et al. [16], who added different kinds of pine needles to adobe blocks (65.48\% and, $9.28 \%$ silt and $26.24 \%$ clay) in framework of comparative study with straw fibers, see Figure 3.

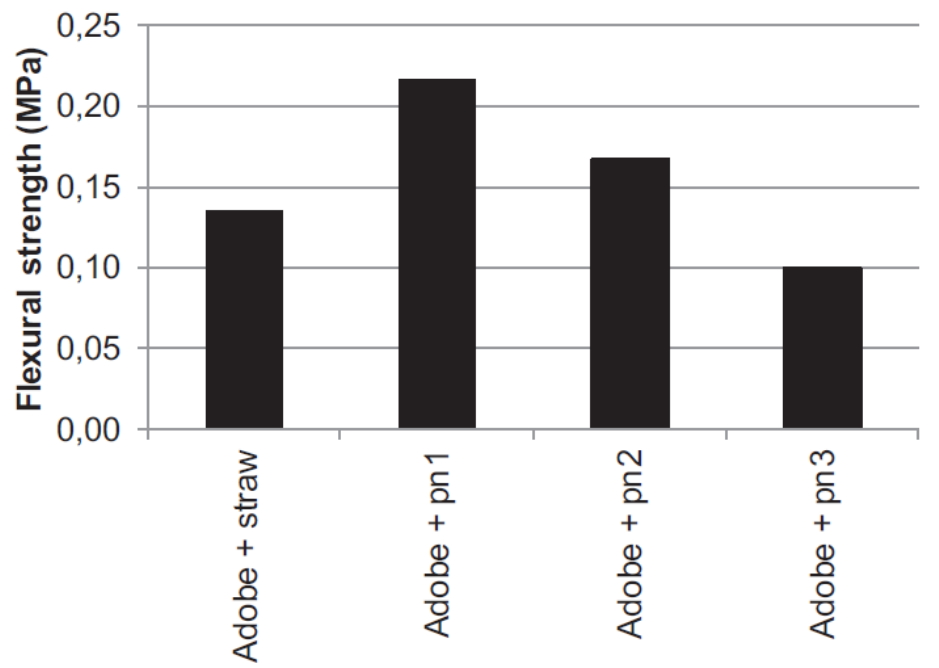

Figure 3-Resistance of adobe bricks reinforced with vegetable fibers [16] 
When embedded in thermosetting, thermoplastic or cementitious matrices [17], important composite materials can be crafted out of natural fibers. For construction fields, thermosetting matrices are the mostly applied ones, mainly epoxy resin-based matrices [18][19]. As composites used for external reinforcement, Yan et al. [20] studied flax fiber reinforced polymers FFRP under flat coupon tensile tests as a candidate for concrete confinement. In this study, a set of confined concrete cylinders from different strength rates (27.5 MPa and 32.8MPa) with bidirectional flax woven with different thicknesses were tested under uniaxial compression. Tests results exhibited remarkable enhancements in the ductility as well as the ultimate strength, around $51 \%$ increase in case of using 9 layers of FFRP with $32.8 \mathrm{MPa}-$ cylinders. Similar outcome was attained when Sen et al. [21] performed a comparative study between sisal/jute composites and carbon/glass composites to confine concrete cylinders. Indications stated in this study demonstrated that it is fairly comparable the axial load capacity increment obtained by sisal (66\%) to that of carbon's $(83 \%)$; especially since natural fibers FRP showed higher ductility and very similar confinement strength of GFRP's (17-18 $\mathrm{MPa})$. The latter research coincided with the findings of Yan et al. [22], whom examined flax FRP comparatively with glass/carbon FRP, regarding the enhancements of the compressive strength and fracture energy [23] of concrete cylinders externally strengthened with.

In another trend of application, researchers suggested using natural fibers combined with synthetic fibers in hybrid composites, through which good mechanical properties, less footprint of carbon and economic advantages can be guaranteed [24][25][26]. In a study carried out by Padanattil et al. [27], concrete cylinders with compressive strength of $23 \mathrm{MPa}$ confined with epoxy-based hybrid sisal-glass reinforced polymers were studied under axial compressive loading. Thereafter, the results were compared with different synthetic fibers composites and yet demonstrated better behavior, if compared with GFRP-confined samples, in terms of deformability, ductility and resistance, Figure 4.

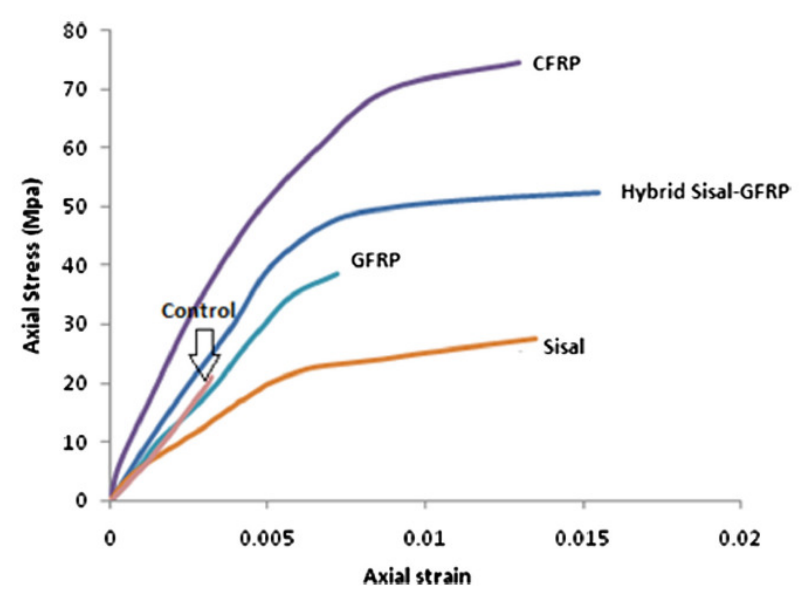

Figure 4-Stress-strain diagram of FRP strengthened samples [27]

\section{Natural fibers composites and the strengthening of the built heritage}

As the natural fibers provide good but limited enhancements to materials of high stiffness, such as concrete, see Figure 4, a new trend of research focusing on using them for external strengthening for weak structures has emerged.

\subsection{Historical masonry behavior}

Masonry structures show a significant behavior under axial compression loading, however, when masonry undergoes eccentric loads, seismic and out-of-plane loading, vulnerability owing to tensile stresses arises as a serious threat. For instance, Marcari et al. [28] studied the in-plane shear behavior of unreinforced masonry walls and observed sharp post-peak softening, limited ductility and low load carrying capacity, Figure 5. This trait might conditionally vary depending on the homogeneity, the variability of the different types of constituent materials and the structural function of the masonry (arch, walls, columns. etc.) [29]. 
a)

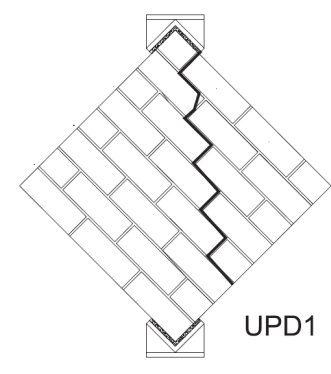

b)

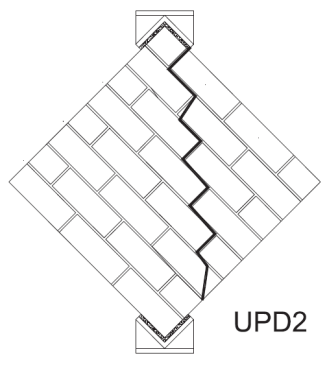

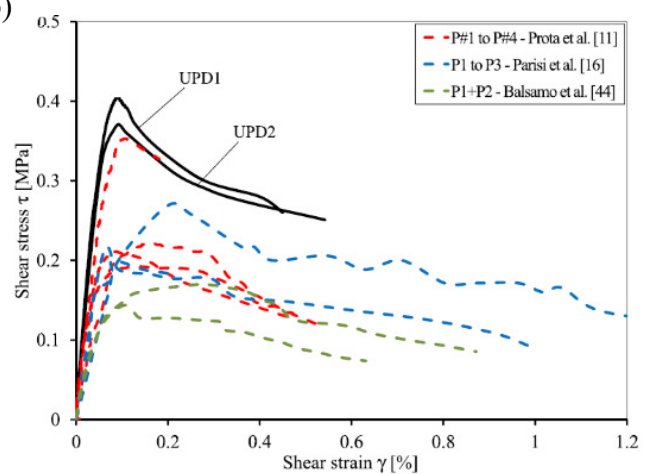

Figure 5- a) Masonry in-plane damage pattern, b) unreinforced masonry in-plane behavior [28]

In addition to the significant results, in terms of tensile strength and energy absorption achieved by natural fibers composites (NFCs), the aptness of employment of these sustainable fibers for strengthening of built heritage and existing buildings is significantly growing. Further, their meeting to the compatibility criterion required for built heritage interventions by Venice Charter [30] and Cracow Charter [31] presents them as an appealing alternative to synthetic fibers.

The practical implementation of NFCs as external-based reinforcement systems has been limitedly employed in a frame of TRM/FRCM [32] when embedded into lime [33][34] or cement matrices [35][36] to strengthen masonry walls [37] [38]. Yet, this solution showed significant developments of mechanical properties. Such solution was also studied as a hybrid composite materials conducted by consequent layers of natural fiber meshes and non-organic fabrics (sisal /glass) embedded into $10 \mathrm{wt} \%$ cement particles and achieved high flexural strength [39].

\subsection{Mechanical Improvements of structural components strengthened with NFCs}

Aiming at a better understanding of the contribution of NFCs to promote the mechanical behavior of structural elements strengthened with, researchers conducted different testing methodologies to accomplish so. When used as a seismic retrofitting system, the contribution of NFCs to improve the in-plane shear response of masonry was experimentally studied throughout shear tests, such as diagonal compression test (DCT). Both clay brick and tuff masonry have shown significant performance when strengthened with NFCs, e.g. hemp fibers [40]. In the latter study, Menna et al. [40], Figure 6, assessed the adequacy of hemp grids embedded into two different matrices (lime and

a)

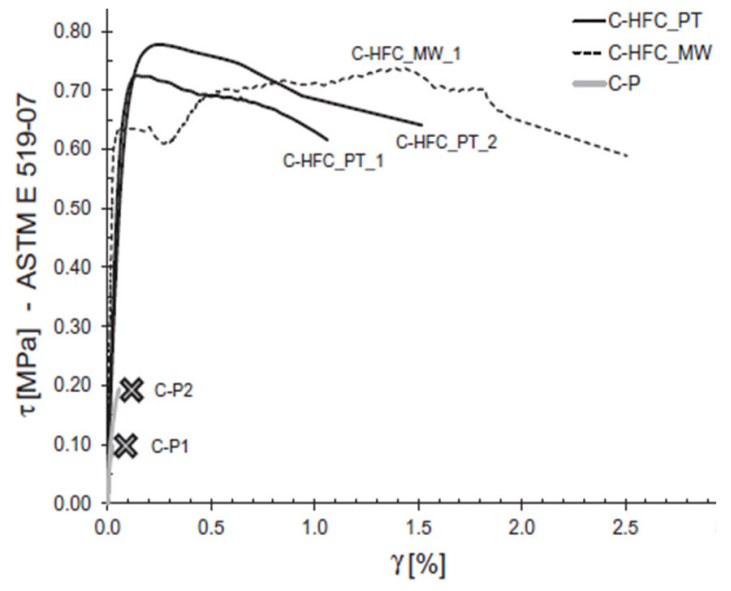

b)

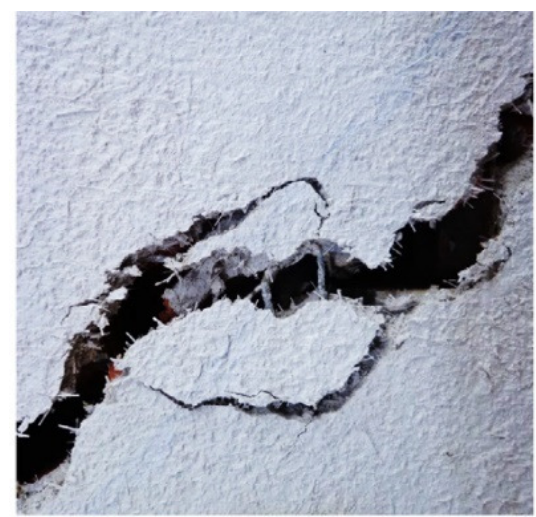

Figure 6- a) Strength increase of clay masonry, b) fibers rupture [40] 
pozzolanic) to strengthen such masonry panels and consequently they adduced significant increments in the shear strength and ductile behavior. Furthermore, bridging phenomena and fibers rupture along the diagonal crack pointed out that the fibers reached their maximum tensile capacity.

Similarly, Olivito et al. [41] studied the effectiveness of NFCs casted from hemp, flax and glass fibers into cement matrices throughout different typologies (grid and unidirectional diagonal strips) as reinforcements for clay masonry walls. Afterward, it was observed that the load carrying capacity, ductility and deformability differ correspondingly to the matrix kind also that flax grid endowed the highest increment of strength (around 90\%), Figure 7. On the other hand, in spite of glass-TRM provided higher ductility than flax-TRM, masonry strengthened with glass-TRM experienced delamination phenomena and sudden collapse of the reinforcements. These results are in a good agreement with numerical results of sisal fibers based-TRM solution, according to [42], where a macro-model was developed and validated to predict the shear performance of masonry panels retrofitted with sisal-TRM.

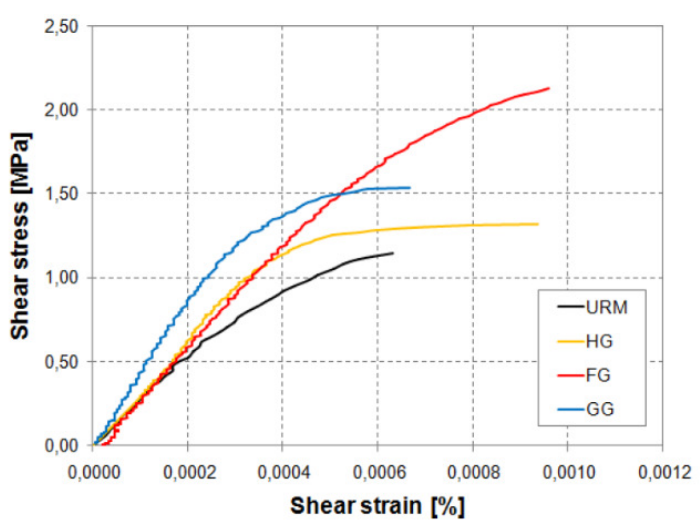

Figure 7-Shear stress-strain diagram [41]

The upgraded out-of-plane response of masonry walling elements repaired or strengthened with NFCs was also detected under eccentric compression tests. In a study by Cevallos et al. [43], woven flax grids and PBO (polyparaphenylene benzobisoxazole) fibers were independently impregnated in lime-based matrix and employed as TRM. Consequently, the results delivered proposed that even though flax fibers have weaker mechanical properties than PBO, their composites outperformed the PBO composites and showed more sufficiency to strengthen historical masonry walls. That conclusion was reliant on the higher strength attained (more than $25 \%$ over PBO-strengthened walls), higher ultimate strains and absence of debonding if compared to PBO-TRM. Another concordant results, considering the study of [44], assured that the capacity of flax-FRCM to transfer the loading to the substrate to release the stored energy, is a preferential aspect that highlights their compatibility to repair damaged masonry. Additionally, the higher bending moment under eccentric loading, good deformability and the ability to restore stiffness might extend the possibility of applying this repairing system to different kinds of loads [43] [44].

The capability of NFCs to sustain the tensile stresses when applied as external reinforcements for masonry arches revealed important promotions in their global behavior if compared to FRP systems. Loccarini [45] characterized the behavior of earthen masonry arches strengthened with jute-TRM along their extrados and intrados simultaneously with specimens anchored with the jute fabrics wraps. Consequently, the reinforcement strips were capable to convey the loading and modify the failure mechanisms by preventing the four-hinge mechanism, enhancing by that the load bearing capacity over $100 \%$.

The diversity of the mechanical enhancements that are possible to gain by NFCs might vary according to reinforcements configurations [41]; as well as the conditions of application, e.g. matrix layers thicknesses [36]; reinforcements layers numbers. etc. This issue has been confirmed in framework of actual case studies [46] where different levels of stability and ductility were delivered through using different typologies.

\subsection{Tensile and bonding behavior of NFCs}

Generally, the mechanical properties of natural fibers composites, namely tensile, bond strength and Young's modulus, significantly increase by including the fibers, since they have much higher tensile strength than the matrices themselves. However, the fact that the fiber content up to an optimum value or beyond combined with the several 
technical processes conditions, such as fibers direction, are important factors that control the efficiency of the NFCs and may compromise the global performance of the composites [18].

In order to assess the competency of TRM tensile characteristics to improve the mechanical response of masonry panels, researchers performed uniaxial direct tensile tests, according to standards [47][48]. These tests have provided a considerable insight in composites tensile properties. By conducting tensile tests on NFCs manufactured from (sisal, jute and hemp) and separately embedded in different matrices (pozzolanic-lime and resins), Codispoti et al [37] characterized the efficiency of this system to resist tensile stresses. Subsequently, they concluded by that even if lime mortar-based NFCs showed lower tensile strength than resins-based NFCs, they have delivered higher ductility and deformability. As a result, this issue requires further investigation especially when applied to weak masonry substrates. A comparable study was performed by authors [34] and reported different tensile strengths when they applied lime matrix in different thicknesses. Thus, the main trait observed was the higher the thickness is, the less ability to distribute the stress along the composites and the lower tensile strength. In terms of failure mechanisms, researchers detected a similar trend of developing the matrix cracking patterns that occur in a gradual manner starting by the formation of the first crack and later ending up by several regular cracks in parallel to the stiffness loosing [49] [34] [50]. The characterization of the adhesion stresses in fiber-to-matrix level is usually achieved throughout pull-out tests carried out on a fiber (mostly yarn) embedded into the matrix specimen [51]. Asprone et al. [52] performed pull-out tests on hemp strings and bundles, with different embedment lengths, coated with latex and resins and impregnated into pozzolana-based matrix. The results obtained revealed that latex delivered good degradation protection to the fibers and improved the bond strength, especially in case of short-embedded fibers. According to [53], the three tested fibers (sisal, curauà and jute) as reinforcements for cement-based matrix exhibited various behaviors depending on the length $(5,10$ and $25 \mathrm{~mm})$ especially in the post peak phase, namely in terms of ductility, see Figure 8.
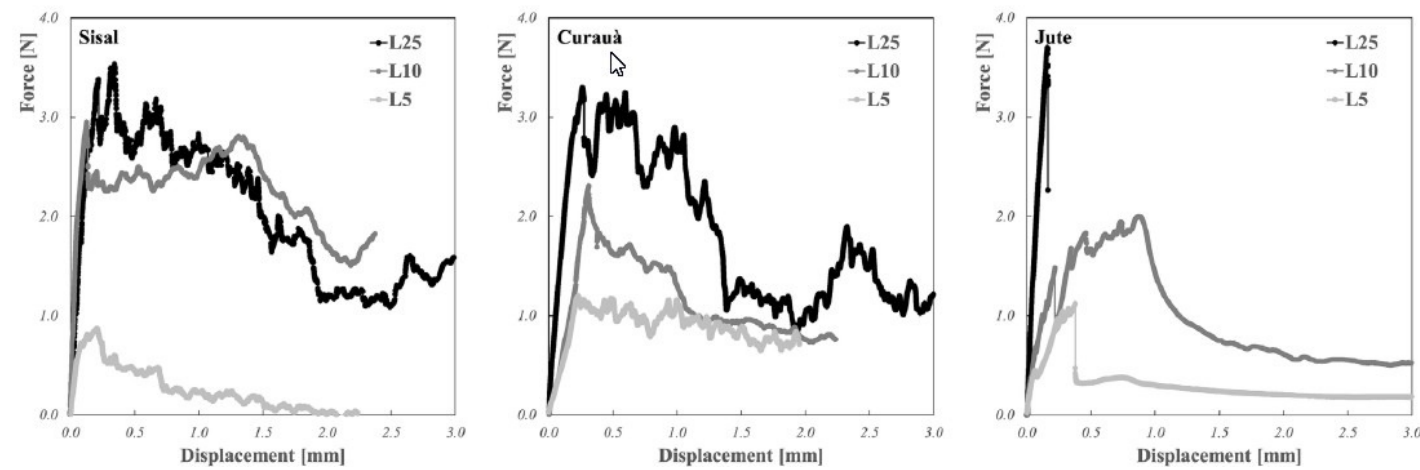

Figure 8- Typical pull-out behavior of natural fibers [53].

Essentially, the bond behavior at matrix-to-substrate level is governed by the two main factors of the adhesive nature and the mechanical characteristics of the substrate. Failure mechanisms can vary therefore, as depicted in Figure 9 [50]. When the adhesive has lower strength than the substrate, a probable fracture in smooth surfaces within the interface in between might occur under so-called adhesive fracture. The cohesive failure takes place through the material (either the adhesive or the substrate). When this type of failure is combined with smooth fracture within the interfacial surface, it results in mixed fracture. To investigate the bond behavior within the interfaces between NFCs and masonry substrates, single or double lap shear bond tests have been employed through literature. In a comparative study between PBO and flax lime-based TRM, Olivito et al [54] observed through double-lap test that bond stress

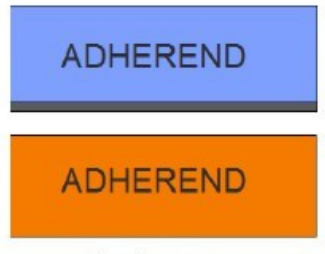

Adhesive Fracture

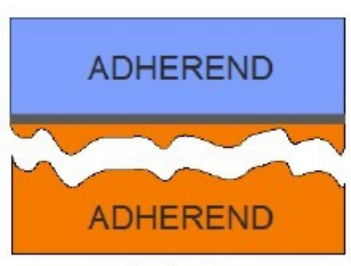

Cohesive Fracture

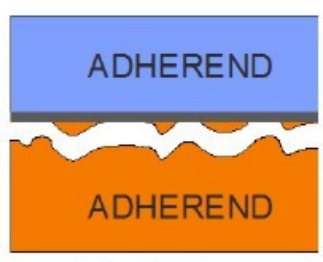

Mixed Fracture

Figure 9-Possible failure mechanisms at adhesive-substrate level [50] 
values of flax composites are similar to the ones of PBO, which indicated that PBO fibers exploited less than $30 \%$ of their mechanical capacity unlike flax fibers. Moreover, the progressive cracking detected with flax-TRM demonstrated better ductile behavior than PBO that had a sudden delamination, see Figure 10, which is concordant with what other studies reported [43] [44].

a)

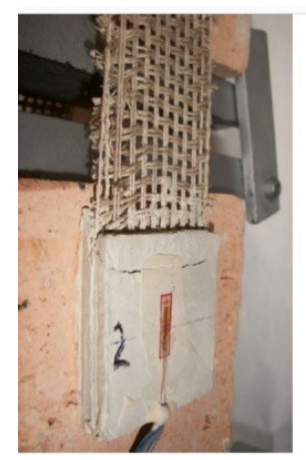

b)

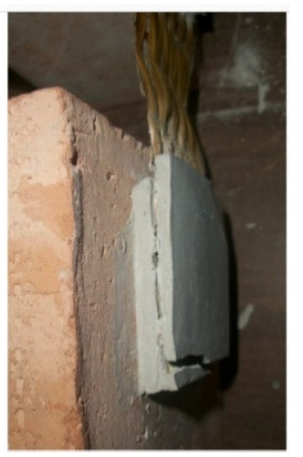

Figure 10-Failure modes of: a) Flax-TRM, b) PBO-TRM [54]

\section{NFCs and challenges}

In spite of natural fibers enable good bonding strength in the interface with matrices, their life cycle can be severely affected when embedded into inorganic matrices such as lime mortar or cement. Natural fibers have polar nature whereas the matrices have nonpolar nature, an issue that can interduce incompatibility problems when manufacturing the NFCs [55]. Every single natural fiber constitutes of several elementary natural fibrils joined together by means of a matrix of pectin [56], which is a complex structure [57]. In turn, every elementary fibril has an essential structure of three successive areas, as depicted in Figure 11. These areas are: the middle lamella that contains lignin, pectin, hemicellulose; the primary cell wall containing hemicellulose and cellulose; the secondary cell walls (S1, S2 and S3) contain mainly cellulose [56-61].
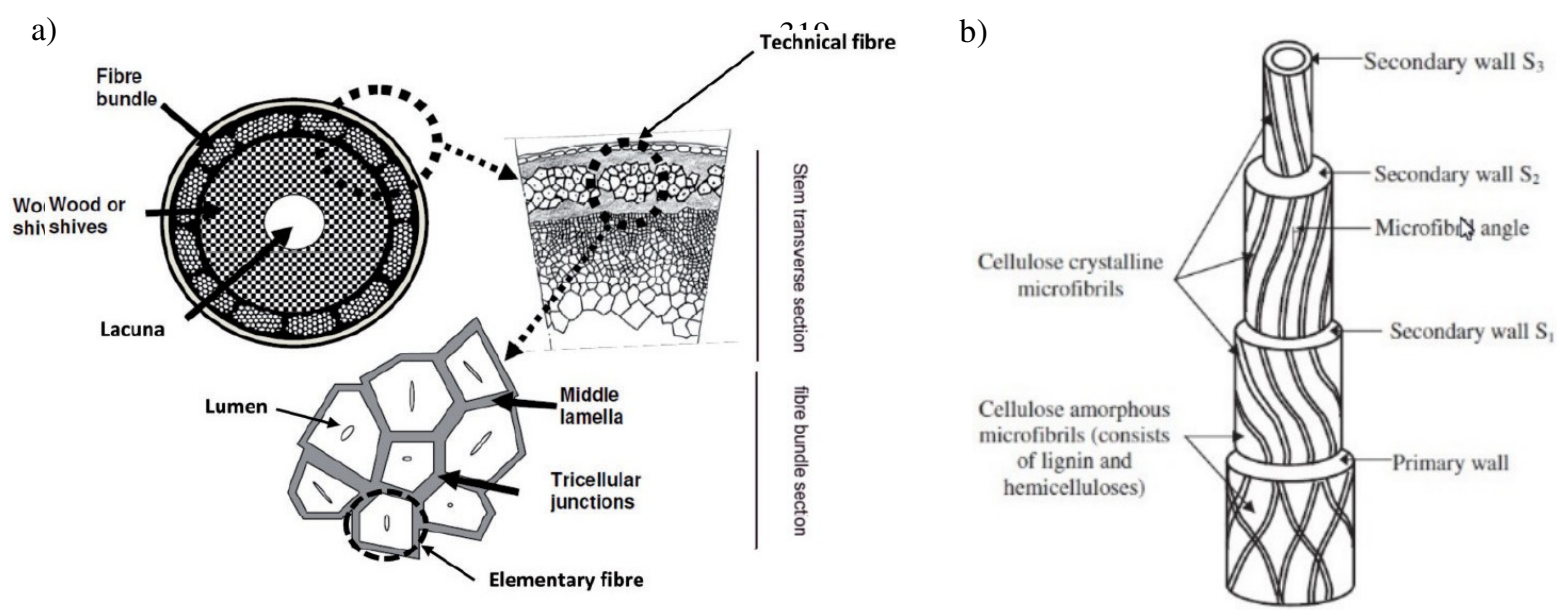

Figure 11-a) the structure of the technical natural fiber [57] , b) natural elementary fibril structure [72]

The crystalline materials, namely cellulose, are responsible for the good mechanical properties of the fibers, i.e. the tensile strength and Young's modulus. On the other hand, the other materials, hemicellulose acts as compatibilizer, lignin, pectin and waxes provide adhesives and matrices, are amorphous and have many irregularities [60]. These amorphous materials are rich with hydroxyl groups $(\mathrm{OH})$ that result in a hydrophilic nature in the most of the natural plant fibers. These hydroxylic groups have extreme affinity to water molecules and tend to intensively bond with them. Accordingly, when embedding these fibers into inorganic matrices and especially the hydrophobic lime-based 
This paper can be found at https://doi.org/10.1016/j.matpr.2020.02.206

matrices, serious impairments in their mechanical performance emerge as an actual challenge. These challenges are due to the high-rate water uptake, represented by the diminishing of the efficiency to transfer tensile stresses.

Generally, the bond behavior between the fiber and the matrix occurs by means of mechanisms of mechanical interlocking, electrostatic bonding, chemical bonding and inter-diffusion bonding [61][55]. In case of NFCs for strengthening purposes, the mechanical interlocking governs the bonding phenomena relying to a high extent on the roughness of the interface within the fiber-to-matrix surface. However, bonding strengths might be compromised when the fibers absorb moisture from the matrix resulting in fibers swelling and diameter expending. Thereafter, that leads to micro cracking in the surrounding matrix to end up by total debonding or local delaminations [59].

To overcome the aforementioned drawbacks, researchers proposed various solutions and treatments either at matrix level, by including additive materials, or by subjecting the fibers themselves to a chain of treatments that can be physical, thermal or chemical [62]. In this paper, the chemical treatments of low cost and easy application are of a main focus prompted by the aim of possible applications to natural fibers for structural strengthening of historical constructions. Moreover, since the lime mortar used for this field has shown significant compatibility to masonry panels, the treatments derived from additive materials to the matrix may dilute this key trait.

Through literature, various chemical treatments were exploited to reduce the hydrophilic nature of the natural fibers. Hence, the chemical modification targets on degrading of the hydroxylic groups or/and occupying these groups by their grafting with different reagents. The reagents have free radicals that have affinity to $(\mathrm{OH})$ functional groups as so a weak reactivity with water molecules is achieved. Different hydrophobic treatments were used [58-62] such as acetylation [63], alkylation [64], silanization, acrylation, benzylation; treatments with isocyanate, permanganate, peroxide, titanate, zirconate; maleated anhydride (MA) grafted coupling agents. Among these treatments, alkali treatments, MA grafting, acetylation and silane treatments are the most common and studied with plant fibers as surface modifiers. Alkaline treatment is usually conducted using $\mathrm{NaOH}$ that degrades the non-cellulosic compounds (hemicellulose the most hydrophilic, lignin, etc.) exposing by that cellulosic materials that have better crystallinity index. Fiore et al [64] applied alkali treatment on kenaf fibers for $48 \mathrm{hs}$ and $144 \mathrm{hs}$ and reported that the treatment with $6 \% \mathrm{NaOH}$ for $48 \mathrm{hs}$ improved the compatibility to the hydrophobic resin matrix and mechanical properties. However, after $144 \mathrm{~h}$-treatment, the tensile strength of the treated fibers was less than that of the untreated ones. When applying acetylation to flax fibers, Bledzki et al [63] observed high tensile strength and moisture absorption resistance due to extraction of the waxy and non-cellulosic components. Though, the increase of the acetylation degree (beyond $18 \mathrm{wt} \%$ ) led to an excessive degradation of cellulose which in turn resulted in decrease of the mechanical behavior. In addition to increasing the mechanical properties of natural fibers, maleic anhydride has been noticed to improve the hydrophobicity of natural fiber surfaces. In parallel, Stamboulis et al. [65] reported that when applying MA treatment to flax fiber composites, they experienced $30 \%$ less moisture uptake than that with the green flax fibers. A concordant hydrophobicity was also attained in a study by authors [66] where they used silane treatment for hemp fibers, where a condensation reaction between hydrolyzed silane and hydroxyl groups of hemp resulted in low affinity to water.

Nevertheless, to comply with the sustainability of natural fibers, many researchers have recommended sustainable and bio-based remedies that may afford considerable enhancements to natural fibers hydrophobicity, such as fatty acids, plants oil, waxes [67], etc. For instance, Wei et al. [68] studied fatty acids derived from canola vegetable oil to improve the hydrophobicity of cellulosic nanofibers, and accordingly they reported good hydrophobic behavior through contact angle test (increase from $23^{\circ}$ to $62^{\circ}$ ). Stearic acid is another fatty acid that has been studied for long time and showed considerable hydrophobic trait when grafted onto different bio-plant-based surfaces [69]. Ye et al. [70] also examined the efficiency of stearic acid grafted onto bio-based film of soy beans proteins to enhance water absorption resistance and subsequently, good hydrophobicity (74\%-increment) was attained, however, the tensile strength decreased if compared to the non-grafted samples. Most recently, a promising bio-based remedial approach depending on using enzymes to deliver higher water absorption resistance has been studied [3] [60] [71]. Enzymes play a crucial role as a catalyst, mediator and non-cellulosic materials degrader. It is known that enzymes such as xylanase, laccase, lipase and oxidases have good capability for the delignification. These bio-based treatments can be found commercialized or prepared through fungal treatments [72], e.g. white rot fungus and taramites hirsute. For example, not only noticeable increase in moisture absorption resistance (20-45\%) and mechanical properties were obtained when authors [73] treated abaca fibers by fungamix and natural enzyme, but also the improvements acquired by these bio-based modifiers exceeded those perceived by MA. 


\section{Conclusion}

Natural fibers are getting a huge interest amongst researchers owing to their sustainable, economical and good mechanical properties when employed in different composites. For applications in strengthening and repairing of weak structures, such as historical masonry, natural fibers composites (NFCs) may outperform synthetic fibers composites in terms of compatibility and deformability under seismic loads. Nevertheless, many factors might affect the performance and durability of NFCs; environmental factors represented mainly in weathering and aging; thermochemo-physical characteristics, i.e. hydrophilicity. Therefore, apart from the non-bio-based coating systems, many bio-based treatments were recommended by researchers to overcome such drawbacks. Hence, the effects of treatments application procedures and conditions, the dependency between fiber content and mechanical behavior of the composites and long-term durability have denoted the need for further studies.

\section{References}

[1] C. Faella, E. Martinelli, E. Nigro, and S. Paciello, "Shear capacity of masonry walls externally strengthened by a cement-based composite material: An experimental campaign," Constr. Build. Mater., vol. 24, no. 1, pp. 84-93, 2010.

[2] P. B. Lourenço, Computational strategies for masonry structures, vol. 70, no. 08. 1996.

[3] O. Faruk, A. K. Bledzki, H. P. Fink, and M. Sain, "Biocomposites reinforced with natural fibers: 20002010," Prog. Polym. Sci., vol. 37, no. 11, pp. 1552-1596, 2012.

[4] A. K. Mohanty M. Misra G. Hinrichsen, "Biofibres, biodegradable polymers and biocomposites: An overview," Macromol. Mater. Eng., vol. 276/277, pp. 1-24, 2000.

[5] M. Ali, X. Li, and N. Chouw, "Experimental investigations on bond strength between coconut fibre and concrete," Mater. Des., vol. 44, pp. 596-605, 2013.

[6] Z. Li, L. Wang, and X. Wang, "Compressive and flexural properties of hemp fiber reinforced concrete," Fibers Polym., vol. 5, no. 3, pp. 187-197, 2004.

[7] I. Merta and E. K. Tschegg, "Fracture energy of natural fibre reinforced concrete," Constr. Build. Mater., vol. 40, pp. 991-997, 2013.

[8] H. U. Bin et al., "Enhanced flexural performance of epoxy polymer concrete with short natural fibers," vol. 61, no. 8, pp. 1107-1113, 2018.

[9] B. Hu et al., "Enhanced flexural performance of epoxy polymer concrete with short natural fibers," Sci. China Technol. Sci., vol. 61, no. 8, pp. 1107-1113, 2018.

[10] J. M. L. Reis, "Fracture and flexural characterization of natural fiber-reinforced polymer concrete," Constr. Build. Mater., vol. 20, no. 9, pp. 673-678, 2006.

[11] A. Mesbah, J. C. Morel, P. Walker, and K. Ghavami, "Development of a Direct Tensile Test for Compacted Earth Blocks Reinforced with Natural Fibers," J. Mater. Civ. Eng., vol. 16, no. 1, pp. 95-98, 2004.

[12] F. Parisi, D. Asprone, L. Fenu, and A. Prota, "Experimental characterization of Italian composite adobe bricks reinforced with straw fibers," Compos. Struct., vol. 122, pp. 300-307, 2015.

[13] Y. Millogo, J. C. Morel, J. E. Aubert, and K. Ghavami, "Experimental analysis of Pressed Adobe Blocks reinforced with Hibiscus cannabinus fibers," Constr. Build. Mater., vol. 52, pp. 71-78, 2014.

[14] L. Turanli and A. Saritas, "Strengthening the structural behavior of adobe walls through the use of plaster reinforcement mesh," Constr. Build. Mater., vol. 25, no. 4, pp. 1747-1752, 2011.

[15] H. Danso, D. B. Martinson, M. Ali, and J. B. Williams, "Physical, mechanical and durability properties of soil building blocks reinforced with natural fibres," Constr. Build. Mater., vol. 101, pp. 797-809, 2015.

[16] F. Jové-sandoval, M. M. Barbero-barrera, and N. Flores, "Assessment of the mechanical performance of three varieties of pine needles as natural reinforcement of adobe," vol. 187, pp. 205-213, 2018.

[17] K. T. WAN and J. Parris, "Investigation of Natural Fibre Reinforced Cementitious Composite for Structural Retrofitting of Building Structures," IABSE Symp. Rep., vol. 106, no. 7, pp. 623-629, 2016.

[18] H. Ku, H. Wang, N. Pattarachaiyakoop, and M. Trada, "217.A review on the tensile properties of natural fiber reinforced polymer composites," Compos. Part B Eng., vol. 42, no. 4, pp. 856-873, 2011.

[19] T. Sen and H. N. J. Reddy, "Strengthening of RC beams in flexure using natural jute fibre textile reinforced composite system and its comparative study with CFRP and GFRP strengthening systems," Int. J. Sustain. Built Environ., vol. 2, no. 1, pp. 41-55, 2014.

[20] B. Yan, L. Huang, L. Yan, C. Gao, and B. Kasal, "Behavior of flax FRP tube encased recycled aggregate 
concrete with clay brick aggregate," Constr. Build. Mater., vol. 136, pp. 265-276, 2017.

[21] T. Sen and A. Paul, "Confining concrete with sisal and jute FRP as alternatives for CFRP and GFRP," Int. J. Sustain. Built Environ., vol. 4, no. 2, pp. 248-264, 2015.

[22] L. Yan and N. Chouw, "Thin-Walled Structures Natural FRP tube con fi ned fi bre reinforced concrete under pure axial compression : A comparison with glass / carbon FRP,” Thin Walled Struct., vol. 82, pp. 159-169, 2014.

[23] L. Yan, "Plain concrete cylinders and beams externally strengthened with natural flax fabric reinforced epoxy composites," Mater. Struct., vol. 49, no. 6, pp. 2083-2095, 2016.

[24] A. Kumre, R. S. Rana, and R. Purohit, "A Review on mechanical property of sisal glass fiber reinforced polymer composites,” Mater. Today Proc., vol. 4, no. 2, pp. 3466-3476, 2017.

[25] M. Ramesh, K. Palanikumar, and K. H. Reddy, "Mechanical property evaluation of sisal - jute - glass fiber reinforced polyester composites," Compos. Part B, vol. 48, pp. 1-9, 2013.

[26] B. V. Ramnath et al., "Evaluation of mechanical properties of abaca - jute - glass fibre reinforced epoxy composite," vol. 51, pp. 357-366, 2013.

[27] A. Padanattil, K. Jayanarayanan, and M. K.M., "Novel hybrid composites based on glass and sisal fiber for retrofitting of reinforced concrete structures," Constr. Build. Mater., vol. 133, pp. 146-153, 2017.

[28] G. Marcari, M. Basili, and F. Vestroni, "Experimental investigation of tuff masonry panels reinforced with surface bonded basalt textile-reinforced mortar," Compos. Part B Eng., vol. 108, pp. 131-142, 2017.

[29] M. R. Valluzzi, C. Modena, and G. de Felice, "Current practice and open issues in strengthening historical buildings with composites,” Mater. Struct. Constr., vol. 47, no. 12, pp. 1971-1985, 2014.

[30] ICOMOS, "INTERNATIONAL CHARTER FOR THE CONSERVATION AND RESTORATION OF MONUMENTS AND SITES (THE VENICE CHARTER 1964)."

[31] Icomos, "The Charter of Krakow 2000: principles for conservation and restoration of built heritage," Archaeol. Pol., vol. 38, p. 5, 2000.

[32] F. G. Carozzi and C. Poggi, "Mechanical properties and debonding strength of Fabric Reinforced Cementitious Matrix ( FRCM ) systems for masonry strengthening," Compos. Part B, vol. 70, pp. 215-230, 2015.

[33] G. Di Bella, V. Fiore, G. Galtieri, C. Borsellino, and A. Valenza, "Effects of natural fibres reinforcement in lime plasters (kenaf and sisal vs. Polypropylene)," Constr. Build. Mater., vol. 58, pp. 159-165, 2014.

[34] R. S. Olivito, O. A. Cevallos, and A. Carrozzini, "Development of durable cementitious composites using sisal and flax fabrics for reinforcement of masonry structures," Mater. Des., vol. 57, no. May, pp. 258-268, 2014.

[35] Ö. Andiç-Çakir, M. Sarikanat, H. Bahadir Tüfekçi, C. Demirci, and Ü. Halis Erdogan, "Physical and mechanical properties of randomly oriented coir fiber - cementitious composites," Compos. Part B, vol. 61, pp. 49-54, 2014.

[36] F. Qamar, T. Thomas, and M. Ali, "Use of natural fibrous plaster for improving the out of plane lateral resistance of mortarless interlocked masonry walling," Constr. Build. Mater., vol. 174, pp. 320-329, 2018.

[37] R. Codispoti, D. V. Oliveira, R. S. Olivito, P. B. Lourenço, and R. Fangueiro, "Mechanical performance of natural fiber-reinforced composites for the strengthening of masonry," Compos. Part B Eng., vol. 77, pp. 74-83, 2015.

[38] C. Ibarra-Castanedo, S. Sfarra, A. Bendada, X. Maldague, and D. Paoletti, "Nondestructive testing of externally reinforced structures for seismic retrofitting using flax fiber reinforced polymer (FFRP) composites," in Thermosense: Thermal Infrared Applications XXXV, 2013, vol. 8705, p. 87050U.

[39] S. L. M. Ribeiro Filho, P. R. Oliveira, L. M. G. Vieira, T. H. Panzera, R. T. S. Freire, and F. Scarpa, "Hybrid bio-composites reinforced with sisal-glass fibres and Portland cement particles: A statistical approach," Compos. Part B Eng., vol. 149, no. April, pp. 58-65, 2018.

[40] C. Menna, D. Asprone, A. Zinno, A. Balsamo, A. Prota, and M. Durante, "Structural behaviour of masonry panels strengthened with an innovative hemp fibre composite grid," Constr. Build. Mater., vol. 100, pp. 111-121, 2015.

[41] R. S. Olivito, F. Dubois, A. Venneri, and F. Zuccarello, "Experimental And Numerical Analysis Of Masonry Macroelements Reinforced By Natural-Fibre-Composite Materials," 6th Int. Conf. FRP Compos. Civ. Eng., pp. 1-8, 2012.

[42] C. B. de Carvalho Bello, A. Cecchi, E. Meroi, and D. V. Oliveira, "Experimental and Numerical Investigations on the Behaviour of Masonry Walls Reinforced with an Innovative Sisal FRCM System," Key 
Eng. Mater., vol. 747, pp. 190-195, 2017.

[43] O. A. Cevallos, R. S. Olivito, R. Codispoti, and L. Ombres, "Flax and polyparaphenylene benzobisoxazole cementitious composites for the strengthening of masonry elements subjected to eccentric loading," Compos. Part B Eng., vol. 71, pp. 82-95, 2015.

[44] O. A. Cevallos, R. S. Olivito, and R. Codispoti, "Experimental Analysis of Repaired Masonry Elements with Flax-FRCM and PBO-FRCM Composites Subjected to Axial Bending Loads," Fibers, vol. 3, pp. 491-503, 2015.

[45] F.- Loccarini, "Behaviour of rammed earth structures: sustainable materials and strengthening techniques," PhD Thesis, p. 151, 2017.

[46] A. Emami, E. Fehling, and M. Schlimmer, "EXTERNAL STRENGTHENING OF MASONRY STRUCTURES WITH NATURAL FIBERS,” vol. 35, no. 2, pp. 125-135, 2011.

[47] AC434, “ACCEPTANCE CRITERIA FOR MASONRY AND CONCRETE STRENGTHENING USING FABRIC-REINFORCED CEMENTITIOUS MATRIX ( FRCM ) COMPOSITE SYSTEMS Approved February 2013 Previously approved October 2011 ACCEPTANCE CRITERIA FOR MASONRY AND CONCRETE STRENGTHENING USING FABR,” Ac434, no. July 2011, 2013.

[48] CNR-DT $200 \mathrm{R} 1 / 2012$, Guide for the Design and Construction of Externally Guide for the Design and Construction of Externally Bonded FRP Systems for Strengthening Existing Structures Materials , RC and PC structures, masonry structures, no. January 2006. 2015.

[49] F. De Andrade, B. Mobasher, R. Dias, and T. Filho, "Cement \& Concrete Composites Cracking mechanisms in durable sisal fiber reinforced cement composites," Cem. Concr. Compos., vol. 31, no. 10, pp. 721-730, 2009.

[50] R. Codispoti and U. O. CALABRIA, "MECHANICAL PERFORMANCE OF NATURAL FIBERREINFORCED COMPOSITES FOR THE STRENGTHENING OF ANCIENT MASONRY," PhD Thesis, 2013.

[51] U. Nirmal, N. Singh, J. Hashim, S. T. W. Lau, and N. Jamil, "On the effect of different polymer matrix and fibre treatment on single fibre pullout test using betelnut fibres," Mater. Des., vol. 32, no. 5, pp. 2717-2726, 2011.

[52] D. Asprone, M. Durante, A. Prota, and G. Manfredi, "Potential of structural pozzolanic matrix-hemp fiber grid composites," Constr. Build. Mater., vol. 25, no. 6, pp. 2867-2874, 2011.

[53] S. Rocha Ferreira, M. Pepe, E. Martinelli, F. de Andrade Silva, and R. Dias Toledo Filho, "Influence of natural fibers characteristics on the interface mechanics with cement based matrices," Compos. Part B Eng., vol. 140, no. December 2017, pp. 183-196, 2017.

[54] R. S. Olivito, R. Codispoti, and O. A. Cevallos, "Bond behavior of Flax-FRCM and PBO-FRCM composites applied on clay bricks : Experimental and theoretical study," Compos. Struct., vol. 146, pp. 221-231, 2016.

[55] R. Latif, S. Wakeel, N. Zaman Khan, A. Noor Siddiquee, S. Lal Verma, and Z. Akhtar Khan, "Surface treatments of plant fibers and their effects on mechanical properties of fiber-reinforced composites: A review," J. Reinf. Plast. Compos., vol. 38, no. 1, pp. 15-30, 2019.

[56] J. Wei and C. Meyer, "Degradation mechanisms of natural fiber in the matrix of cement composites," Cem. Concr. Res., vol. 73, pp. 1-16, 2015.

[57] F. Bensadoun et al., "Impregnated fibre bundle test for natural fibres used in composites," J. Reinf. Plast. Compos., vol. 36, no. 13, pp. 942-957, 2017.

[58] A. Gandini and M. N. Belgacem, The State of the Art of Polymers from Renewable Resources, no. 2008. Elsevier, 2012.

[59] Z. N. Azwa, B. F. Yousif, A. C. Manalo, and W. Karunasena, "A review on the degradability of polymeric composites based on natural fibres," Mater. Des., vol. 47, pp. 424-442, 2013.

[60] P. Saha, S. Chowdhury, D. Roy, B. Adhikari, J. K. Kim, and S. Thomas, "A brief review on the chemical modifications of lignocellulosic fibers for durable engineering composites," Polym. Bull., vol. 73, no. 2, pp. 587-620, 2016.

[61] K. L. Pickering, M. G. A. Efendy, and T. M. Le, "A review of recent developments in natural fibre composites and their mechanical performance," Compos. Part A Appl. Sci. Manuf., vol. 83, pp. 98-112, 2016.

[62] A. Ali et al., "Hydrophobic treatment of natural fibers and their composites-A review," J. Ind. Text., vol. 47, no. 8, pp. 2153-2183, 2018.

[63] A. K. Bledzki, A. A. Mamun, M. Lucka-Gabor, and V. S. Gutowski, "The effects of acetylation on 
properties of flax fibre and its polypropylene composites," Express Polym. Lett., vol. 2, no. 6, pp. 413-422, 2008.

[64] V. Fiore, G. Di Bella, and A. Valenza, "The effect of alkaline treatment on mechanical properties of kenaf fibers and their epoxy composites," Compos. Part B Eng., vol. 68, pp. 14-21, 2015.

[65] A. Stamboulis and C. A. Baillie, "Environmental Durability of Flax Fibres and their Composites based on Polypropylene Matrix,” AppliedComposite Mater., vol. 7, pp. 273-294, 2000.

[66] A. Rachini, M. Le Troedec, and C. Peyratout, "Chemical Modification of Hemp Fibers by Silane Coupling Agents," vol. 123, pp. 601-610, 2012.

[67] M. Brahmakumar, C. Pavithran, and R. M. Pillai, "Coconut fibre reinforced polyethylene composites: Effect of natural waxy surface layer of the fibre on fibre/matrix interfacial bonding and strength of composites," Compos. Sci. Technol., vol. 65, no. 3-4, pp. 563-569, 2005.

[68] L. Wei, U. P. Agarwal, K. C. Hirth, L. M. Matuana, R. C. Sabo, and N. M. Stark, "Chemical modification of nanocellulose with canola oil fatty acid methyl ester," Carbohydr. Polym., vol. 169, pp. 108-116, 2017.

[69] N. E. Zafeiropoulos, D. R. Williams, C. A. Baillie, and F. L. Matthews, "Engineering and characterisation of the interface in flax fibre / polypropylene composite materials . Part I . Development and investigation of surface treatments," vol. 33, pp. 1083-1093, 2002.

[70] Q. Ye, Y. Han, J. Zhang, W. Zhang, C. Xia, and J. Li, "Bio-based films with improved water resistance derived from soy protein isolate and stearic acid via bioconjugation," J. Clean. Prod., vol. 214, pp. 125-131, 2019.

[71] M. George, P. G. Mussone, and D. C. Bressler, "Surface and thermal characterization of natural fibres treated with enzymes," Ind. Crops Prod., vol. 53, pp. 365-373, 2014.

[72] M. M. Kabir, H. Wang, K. T. Lau, and F. Cardona, "Chemical treatments on plant-based natural fibre reinforced polymer composites: An overview," Compos. Part B Eng., vol. 43, no. 7, pp. 2883-2892, 2012.

[73] A. K. Bledzki, A. A. Mamun, A. Jaszkiewicz, and K. Erdmann, "Polypropylene composites with enzyme modified abaca fibre," Compos. Sci. Technol., vol. 70, no. 5, pp. 854-860, 2010. 